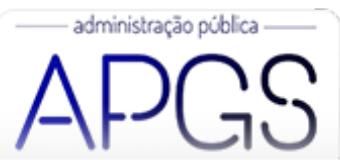

Administração Pública e Gestão Social ISSN: 2175-5787

apgs@ufv.br

Universidade Federal de Viçosa

Brasil

\title{
Apresentação da Coleção Gestão Pública de Livros da SBAP com a ENAP
}

\author{
Ferreira Dias, Thiago \\ Apresentação da Coleção Gestão Pública de Livros da SBAP com a ENAP \\ Administração Pública e Gestão Social, vol. 11, núm. 4, 2019 \\ Universidade Federal de Viçosa, Brasil \\ Disponível em: http://www.redalyc.org/articulo.oa?id=351560525011
}

Esta obra está bajo una Licencia Creative Commons Atribución-NoComercial-SinDerivar 3.0 Internacional. 


\section{Apresentação da Coleção Gestão Pública de Livros da SBAP com a ENAP}

Thiago Ferreira Dias

Universidade Federal do Rio Grande do Norte, Brasil

tfdpe@yahoo.com.br
Redalyc: http://www.redalyc.org/articulo.oa? $\mathrm{id}=351560525011$

Ainda em meados do ano de 2013 nascia a Sociedade Brasileira em Administração Pública (SBAP), com o objetivo de propiciar um espaço institucional de articulação das pós-graduações e profissionais do Campo de Públicas. Foram vários obstáculos, com importantes vitórias e alguns infortúnios, para a SBAP e seus associados nesses 6 (seis) anos de história. Diante dos frutos acadêmicos da associação, assistimos a consolidação do nosso evento nacional denominado Encontro Brasileiro de Administração Pública (EBAP), e várias parcerias estratégicas.

Esta edição especial, ora disponibilizada, é um dos resultados da parceria SBAP e APGS/UFV, processo iniciado no ano de 2018. Ainda é necessário frisar outra valorosa contribuição da SBAP, dentro do contexto de produções acadêmicas na área de Administração Pública; para tanto é necessário voltarmos ao ano de 2015, quando iniciamos um diálogo profícuo com a Escola Nacional de Administração (ENAP).

Inicialmente, foram realizadas parcerias quanto à participação da ENAP nos encontros da SBAP, e reciprocamente o convite a SBAP para participar ativamente de ações da ENAP, incluindo o Comitê Editorial e Conselho Científico da Revista do Serviço Público (RSP), um dos periódicos nacionais da área da Administração Pública mais antigos em circulação no país - desde 1937 -, mantido sob a batuta da ENAP a partir de 1986.

Desta relação surgiu, em meados de 2018, a proposta para que a SBAP capitaneasse junto a ENAP a elaboração de uma coletânea de livros, sob o título de "Coleção Gestão Pública". Vale ressaltar que desde o ano de 2018 a ENAP vem empreendendo esforços na elaboração de materiais instrucionais que colaboram com a sistematização e difusão do conhecimento do Campo de Públicas em produções bibliográficas de excelente qualidade e em língua portuguesa, no qual temos o primoroso exemplo da "Coleção Governo e Políticas Públicas".

Agora, no segundo semestre de 2019, tivemos o lançamento dessa Coleção Gestão Pública, fruto da parceria ENAP e SBAP; um rol de produção bibliográfica muito relevante para área de Administração Pública no país. Esta coleção conta com 11 (onze) livros que versam sobre vários temas, tendo como eixo central o debate e reflexões sobre a administração/gestão pública no contexto brasileiro, quais sejam:

1. Desenvolvimento de carreiras por competências, de autoria de Anielson Barbosa da Silva, Ana Carolina Kruta de Araújo Bispo e Simone Maia Pimenta Martins Ayres.

2. A (Nova) Governança Pública de autoria de Hugo Consciência Silvestre;

3. História do ensino de administração pública no Brasil (1854-2006): antecedentes, ciclos e a emergência do Campo de Públicas, de autoria de Fernando de Souza Coelho;

4. Inovação e tecnologias da comunicação e informação na administração pública, de autoria de Thiago Ferreira Dias, Hironobu Sano e Marcos Fernando Machado de Medeiros;

5. Gestão de pessoas: liderança e competências para o setor público, de autoria de Sandro Trescastro Bergue;

6. Inovação e empreendedorismo no setor público, de autoria de Magnus Luiz Emmendoerfer; 
7. Governança, gestão de riscos e integridade, de autoria de James Batista Vieira e Rodrigo Tavares de Souza Barreto;

8. Ciclo orçamentário brasileiro, de autoria de Antônio Sergio Araújo Fernandes e Thiago Silva e Souza;

9. Comunicação e marketing no setor público: diferentes abordagens para a realidade brasileira, de autoria de Layon Carlos Cezar

10. O Campo do conhecimento em administração pública no Brasil: uma análise histórica a partir do seu contexto e caráter multifacetado, de autoria de Victor Corrêa e Claudia Souza Passador;

11. Compras públicas: para além da economicidade, de autoria de Caio César de Medeiros Costa e Antônio Carlos Paim Terra.

Diante dos títulos expostos é notória a diversidade/abrangência presente nesta coleção. No primeiro livro, Desenvolvimento de carreiras por competências, os autores discutem a necessidade de repensar a carreira no setor público, de modo a esboçar possibilidades do desenvolvimento de carreiras por competências. Já no livro A (Nova) Governança Pública, o professor Hugo Consciência Silvestre traz à tona à análise da Nova Governança Pública, enfoque que privilegia participação via comunidade, redes ou networks e a organização do setor público na sua relação com os usuários. Para materializar as concepções teóricas desta nova vertente, discorre sobre experiências internacionais e nacionais, em especial a experiência de cooperação consorciada no Brasil.

O livro História do ensino de administração pública no Brasil (1854-2006): antecedentes, ciclos e a emergência do Campo de Públicas, do professor Fernando de Souza Coelho, descreve e analisa, cronologicamente, a trajetória do ensino de graduação em administração pública no Brasil entre os anos de 1952 aos anos 2000. Extremamente recomendado para compreendermos o processo de construção do Campo de Públicas no Brasil.

Por sua vez, a obra Inovação e tecnologias da comunicação e informação na administração pública traz o papel da Tecnologia da Informação e Comunicação (TIC) e seus efeitos nas melhorias dos processos internos da administração pública e no aperfeiçoamento da relação Estado-sociedade. Assim, aborda temas como Governo Eletrônico, Governo Digital e Governo Aberto.

O quinto livro, Gestão de pessoas: liderança e competências para o setor público, escrito pelo professor Sandro Trescastro Bergue, reporta ao campo da gestão de pessoas no setor público, com ênfase no papel da liderança como propulsor de melhorias nas organizaçóes públicas e na prestação dos serviços públicos. Por seu turno, o livro Inovação e empreendedorismo no setor público, de autoria do do professor Magnus Luiz Emmendoerfer, busca trazer à baila os temas de inovação e o empreendedorismo e suas possíveis contribuições para a Administração Pública no que concerne à melhoria da qualidade do serviço público e ao aperfeiçoamento da relação entre Estado e Sociedade.

No sétimo livro, denominado Governança, gestão de riscos e integridade, os autores versam sobre os mecanismos de governança, gestão de riscos e integridade (GRC) com o objetivo de compendiar princípios, modelos e práticas que busquem assegurar o efetivo exercício profissional do agente público com vistas a preservar e aumentar o valor dos serviços públicos prestados à sociedade.

No livro intitulado Ciclo orçamentário brasileiro, seus autores detêm-se na explanação do complexo ciclo orçamentário brasileiro, abordando suas especificidades, vantagens e desvantagens, e desafios inerentes ao sistema de planejamento-orçamento governamental. Já o livro Comunicação e marketing no setor público: diferentes abordagens para a realidade brasileira, do professor Layon Carlos Cezar, realiza com maestria o debate sobre marketing e comunicação no contexto da administração pública brasileira, apresentando esses conceitos (e suas ferramentas) na ambiência do setor público.

No décimo livro, Campo do conhecimento em administração pública no Brasil: uma análise histórica a partir do seu contexto e caráter multifacetado, os autores propõem uma análise do contexto de produção científica sobre a administração pública no Brasil, no período compreendido entre os anos de 1937 e 2009 , 
desvelando distintas dimensões - contextual, teórica, técnica e prática - da gestão pública como campo do saber e locus profissional.

Por fim, no livro Compras públicas: para além da economicidade, os autores desenvolvem uma análise esmiuçada sobre o processo de compras públicas, em especial no contexto brasileiro, no qual realizam debate e reflexões quanto às práticas e modelos de compras governamentais a partir de uma visão mais abrangente do que a convencional.

Não obstante, observamos a contribuição decisiva da SBAP na articulação, sistematização e publicização da produção científica de administração pública no Brasil nesta década, apoiando a consolidação desse campo do saber e a formação de profissionais na área. Espera-se que essas obras ora apresentadas tragam à baila reflexões para o aperfeiçoamento das ações públicas nos três níveis de governo.

O e-book de todos os livros da Coleção Gestão Pública da SBAP com a Escola Nacional de Administração Pública, ilustrada - abaixo - por três das 11 obras, está disponível para download no repositório da ENAP, pelo link: https://repositorio.enap.gov.br/handle/1/4264

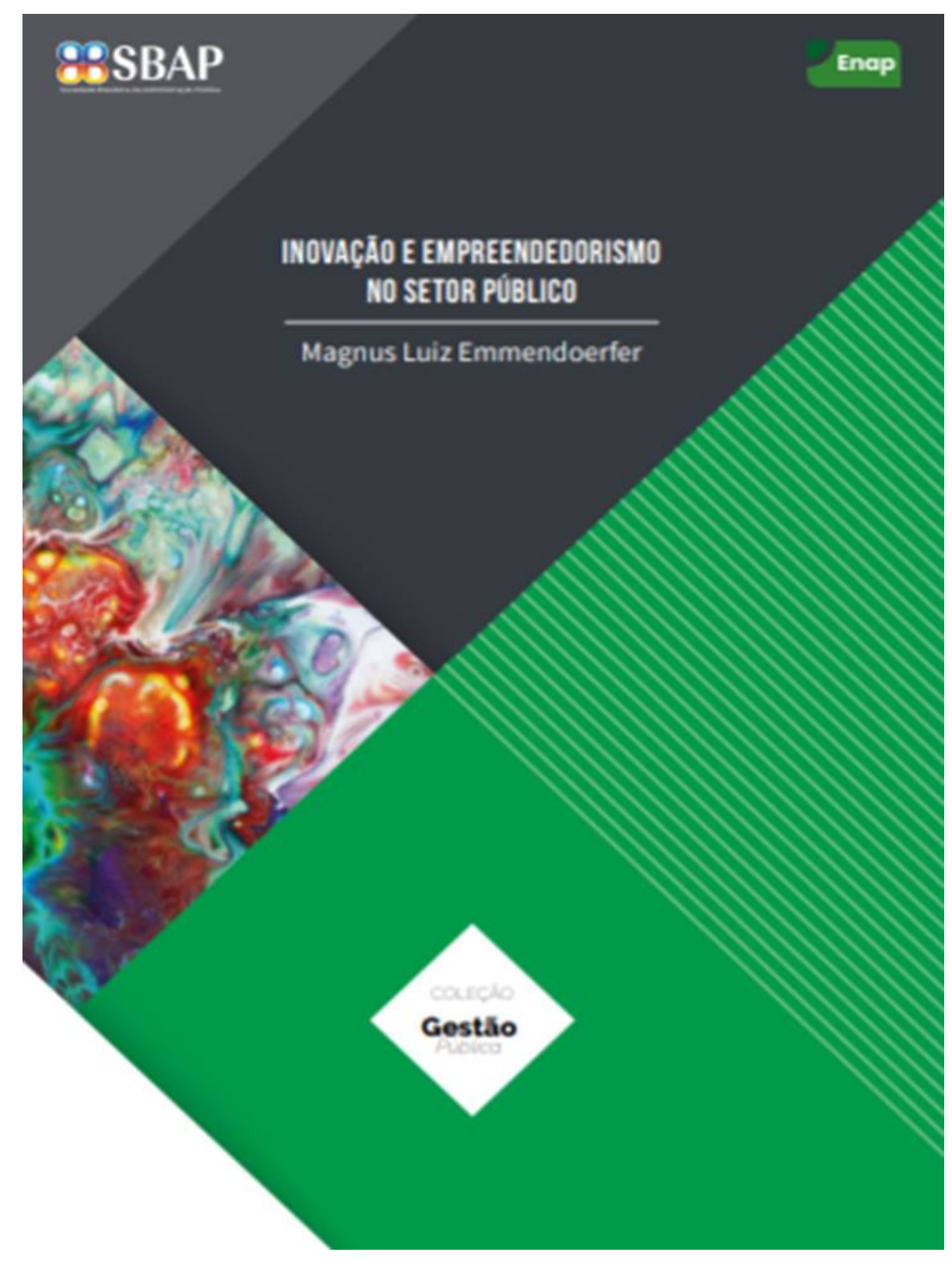




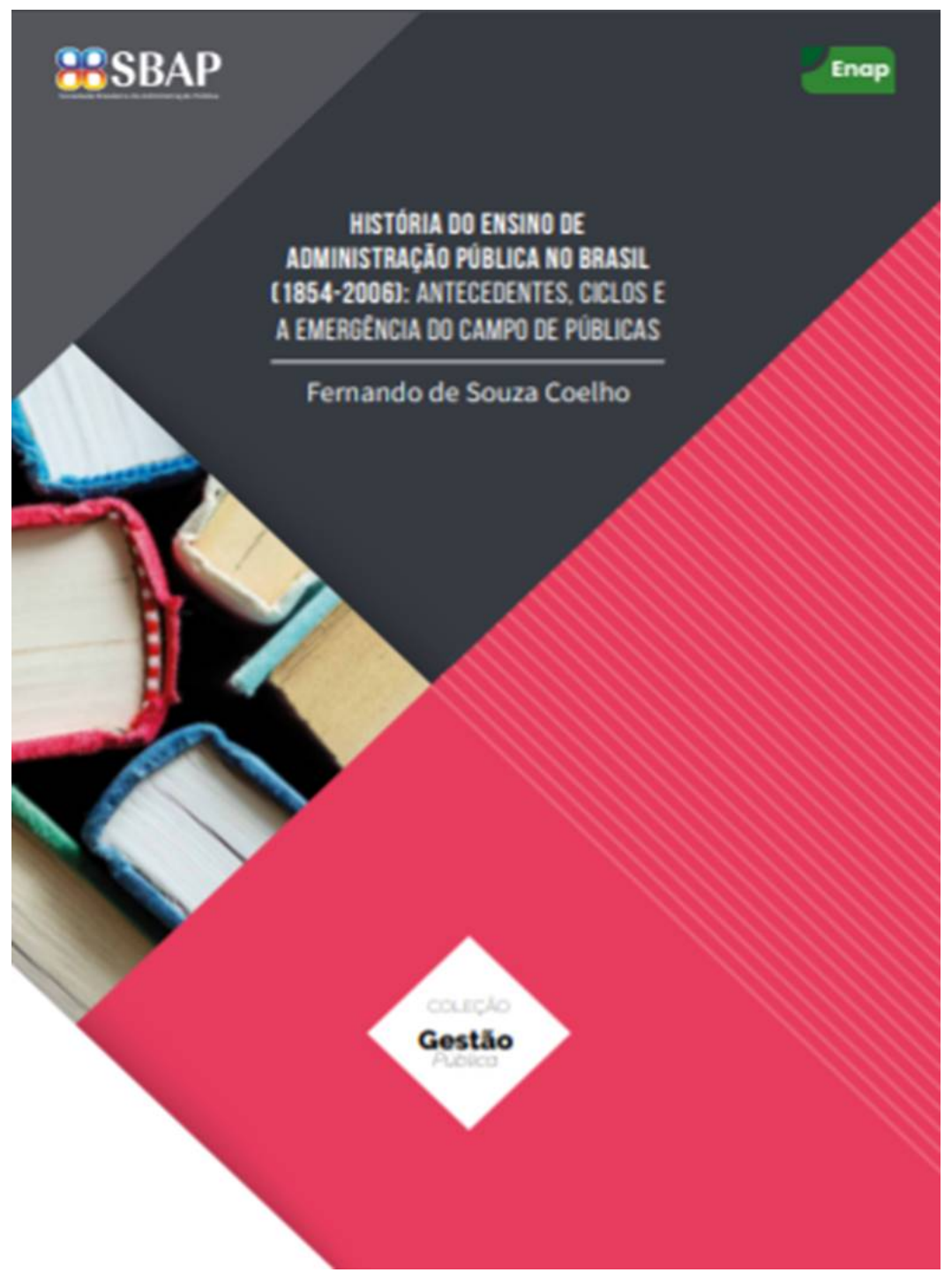




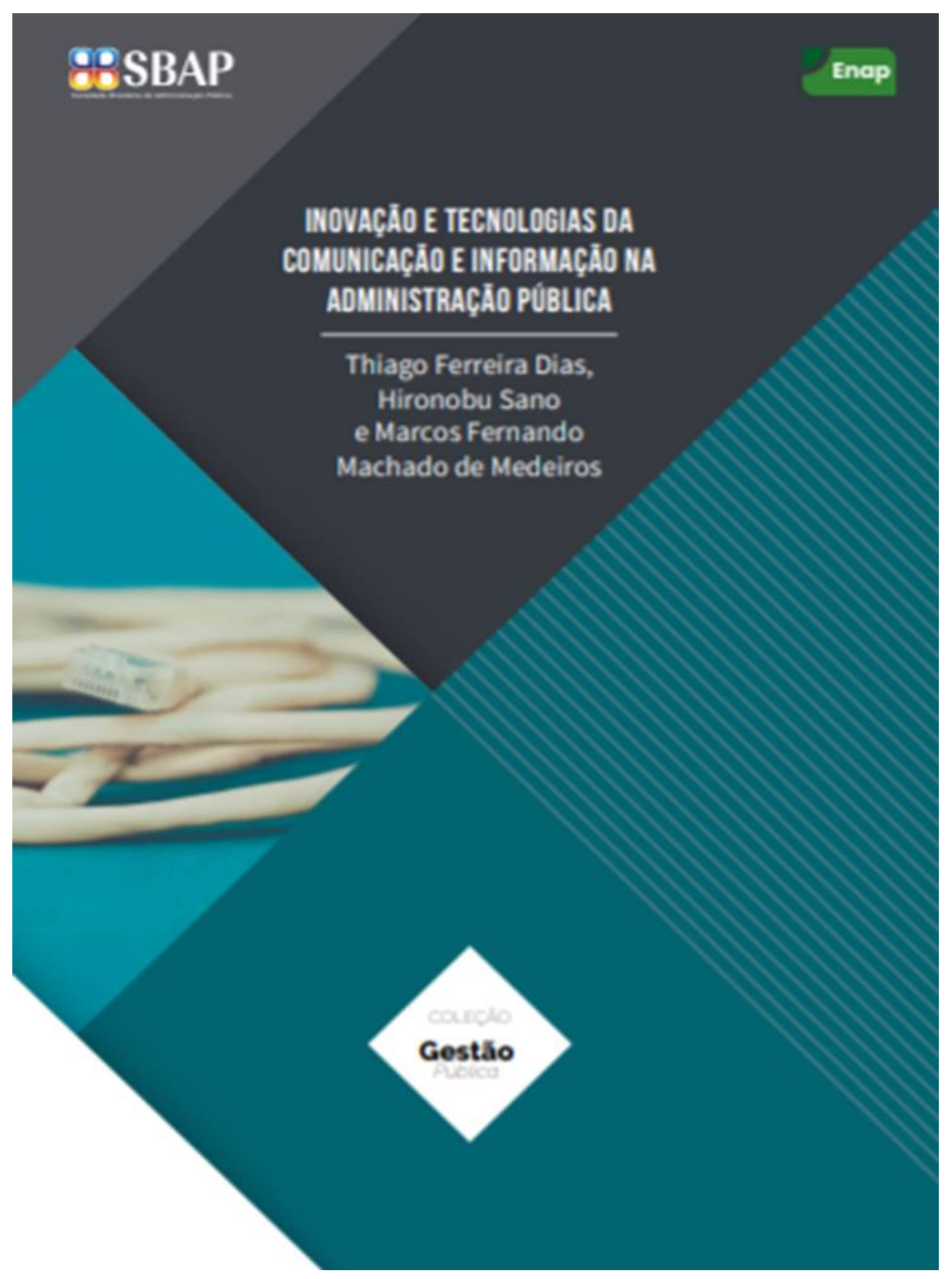

CC BY-NC-ND 